
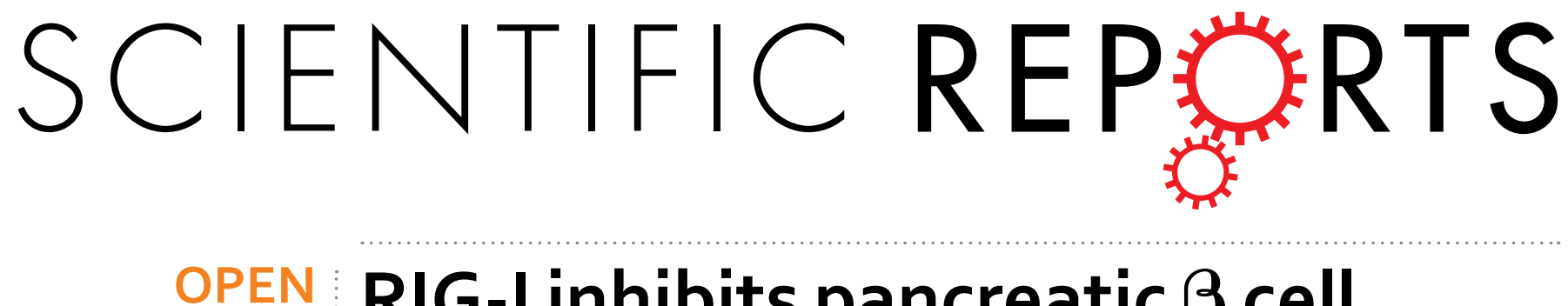

\title{
RIG-I inhibits pancreatic $\beta$ cell proliferation through competitive binding of activated Src
}

Received: 03 March 2016

Accepted: 10 June 2016

Published: 28 June 2016

\author{
Yi Pan ${ }^{1, *}$, GuangMing Li ${ }^{1,2, *}$, HengGao Zhong ${ }^{1,3}$, MeiJuan Chen ${ }^{4}$, TingTing Chen ${ }^{1}$, LiLi Gao ${ }^{1}$, \\ HuiWen Wu $\mathbf{u}^{5}$ \&un Guo ${ }^{1}$
}

Nutrition is a necessary condition for cell proliferation, including pancreatic $\beta$ cells; however, overnutrition, and the resulting obesity and glucolipotoxicity, is a risk factor for the development of Type 2 diabetes mellitus (DM), and causes inhibition of pancreatic $\beta$-cells proliferation and their loss of compensation for insulin resistance. Here, we showed that Retinoic acid (RA)-inducible gene I (RIG-I) responds to nutrient signals and induces loss of $\beta$ cell mass through $\mathrm{G} 1$ cell cycle arrest. Risk factors for type 2 diabetes (e.g., glucolipotoxicity, TNF- $\alpha$ and LPS) activate Src in pancreatic $\beta$ cells. Elevated RIG-I modulated the interaction of activated Src and STAT3 by competitive binding to STAT3. Elevated RIG-I downregulated the transcription of SKP2, and increased the stability and abundance of P27 protein in a STAT3-dependent manner, which was associated with inhibition of $\beta$ cell growth elicited by Src. These results supported a role for RIG-I in $\beta$ cell mass loss under conditions of metabolic surplus and suggested that RIG-I-induced blocking of Src/STAT3 signalling might be involved in G1 phase cycle arrest through the Skp2/P27 pathway in pancreatic $\beta$ cells.

Type 2 diabetes mellitus (T2DM) is increasing at an alarming rate and has become a global challenge. This increase has resulted from the improvement in living conditions and increased intake of carbohydrate, fat and meat in the daily diet, especially for Asian populations. Over-nutrition, and resulting obesity, both trigger chronic inflammation in metabolic tissues (termed meta-inflammation) and contribute directly or indirectly to $\beta$-cell dysfunction, both quantitatively (i.e., the relative decrease in $\beta$-cell mass) and qualitatively (impaired $\beta$-cell insulin secretion), which result in compromised insulin secretion and T2DM ${ }^{1}$. Promoting $\beta$ cell proliferation and their mass compensation associated with the demand for insulin would aid the prevention of type 2 diabetes development efficiently ${ }^{2}$.

Pattern recognition receptors (PRRs) are involved in anti-proliferation activities in pancreatic $\beta$ cells during nutrition metabolism and meta-inflammation, indicating a pivotal role of PRRs in metabolic regulation and $\mathrm{T}_{2} \mathrm{DM}^{3}$. Retinoic acid (RA)-inducible gene I (RIG-I) is a typical intracellular PRR. Upon viral dsRNA challenge, RIG-I is activated and regulates the expressions of various inflammatory cytokines to initiate innate and adaptive immunity to protect the organism. In addition, RIG-I is involved in cell proliferation, differentiation and apoptosis. There is an Src-interacting motif, PxxP, in the N-terminal caspase activation and recruitment domain of RIG-I. The PxxP motif combines with the Src SH3 domain to prevent Src from associating with its downstream substrate ${ }^{4}$.

Src, a non-receptor tyrosine kinase, is activated by many factors, such as high glucose, palmitate, leptin, TNF- $\alpha$ and IFN- $\gamma^{5-9}$. Activation of Src might result in the promotion of survival and proliferation pathways, and even induce malignant tumours $(\mathrm{v} \text {-src })^{10}$. Many cell-cycle regulatory proteins involved in cell proliferation are induced by Src, such as cyclin A, E, D1, A/CDK2 complex, P27 and P53 ${ }^{11-14}$. Active Src induces phosphorylation of P27, and then downregulates its protein level ${ }^{15}$. Protooncogene Src was suggested to counteract the reduction of Skp2 protein effectively, which involves the negative regulation of P27 and plays a proto-oncogenic role in vitro and

${ }^{1}$ Department of Biochemistry and Molecular Biology, Nanjing Medical University, Nanjing, PR China. ${ }^{2}$ Department of Anesthesiology, Huaian First People's Hospital, Nanjing Medical University, Huaian, Jiangsu, PR China. ${ }^{3}$ Medical Center for Digestive Diseases, Second Affiliated Hospital, Nanjing Medical University, Nanjing, Jiangsu, PR China. ${ }^{4}$ The Pre-clinical Medicine College, Nanjing University of Chinese Medicine, Nanjing, PR China. ${ }^{5}$ Laboratory Center for Basic Medical Sciences, Nanjing Medical University, Nanjing, PR China. *These authors contributed equally to this work. Correspondence and requests for materials should be addressed to J.G. (email: Guoj@njmu.edu.cn or Guoj69@aliyun.com) 
in vivo ${ }^{16,17}$. In addition, the transcription factor STAT3 can be activated by Src to regulate Skp2 expression positively ${ }^{18}$. However, the effects of tyrosine kinases on cell-cycle regulatory proteins in pancreatic $\beta$ cells remain unclear.

In the context of obesity or glucolipotoxicity, PRRs in the immune system are activated and are involved in metabolic modulation ${ }^{19,20}$. Glucolipotoxicity and meta-inflammation play critical roles in the development of type 2 diabetes and result in Src activation ${ }^{6}$, together with elevated RIG-I. According to Kim et al., inflammatory responses linked with innate immunity might be affected by obesity ${ }^{21}$, and RIG-I has been reported to be elevated during the innate immune respons $\mathrm{e}^{22}$; therefore, our study aimed to explore the potential association between the two signal molecules.

\section{Materials and Methods}

Reagents. Dulbecco's Modified Eagle’s medium (DMEM), Roswell Park Memorial Institute 1640 (RPMI1640) and foetal bovine serum (FBS) were purchased from Gibco (Carlsbad, CA, USA). Lipofectamine 2000 and Trizol were bought from Invitrogen (Carlsbad, CA, USA). The Reverse Transcription Kit and the SYBR Green PCR Master Mix were obtained from Takara (Otsu, Shiga, Japan). 3-[4,5-dimethylthiazol-2-yl]-2,5 diphenyl tetrazolium bromide (MTT), Type V collagenase, Histopaque-1077 and palmitate were bought from Sigma Aldrich (St. Louis, MO, USA). TNF $\alpha$ was obtained from Perprotech (Rocky Hill, NJ, USA). The Cell-Light ${ }^{\text {TM }}$ EdU DNA Cell Proliferation Kit was obtained from RiboBio (Guangzhou, China). The STAT3 dependent reporter construct pGMSTAT3-Lu was from Genomeditech (Shanghai, China). RIPA lysis buffer, the nuclear and cytoplasmic protein extraction kit, the BCA kit and ortho- Nitrophenyl- $\beta$-galactoside (ONPG) were obtained from Beyotime Inc (Shanghai, China). The antibodies against RIG-I, Cyclin D1, Cyclin E and Cdk2 were purchased from cell signaling technology (Boston, MA, USA). The antibodies against $\beta$ actin and insulin were obtained from BOSTER (Wuhan, China). The antibodies against P21, P27, Src, phospho-Src (Tyr418), STAT3 and phospho-STAT3 were obtained from EnoGene (Enogene Biotech Co. Ltd., China). The SKP2 antibody was purchased from Bioss (Beijing, China). The antibodies against Fluorescein-Conjugated AffiniPure Goat Anti-Rabbit IgG and Rhodamine (TRITC)-conjugated AffiniPure Goat Anti-Mouse IgG were bought from ZSGB-BIO (Beijing, China). The Recombinant Human IGF-1 antibody was from PEPROTECH (Rocky Hill, NJ, USA).

Cell culture and transfection. The pancreatic $\beta$ cell line MIN6 was cultured in DMEM (4.5 g/l glucose) supplemented with $15 \%$ (v/v) FBS, $121 \mu \mathrm{mol} / \mathrm{l} 2$-mercaptoethanol, $100 \mathrm{U} / \mathrm{ml}$ penicillin and $100 \mu \mathrm{g} / \mathrm{ml}$ streptomycin $^{23}$. Transient transfections of plasmid constructs and siRNAs were performed using Lipofectamine 2000, according to the manufacturer's instructions.

Islet isolation, culture and in vitro transfection. Ten-week-old (20-25 g) male imprinting control region (ICR) mice and db/db mice were obtained from the Model Animal Research Center of Nanjing University. Animals were housed individually in standard polycarbonate cages with sawdust bedding. Water and food were available ad libitum. Principles of laboratory animal care were followed and all procedures were conducted according to the guidelines established by the National Institutes of Health. Every effort was made to minimize suffering. This study was approved by the Research Animal Care Committee of Nanjing Medical University (Nanjing, China). Islet isolation and culture techniques were as previously described ${ }^{24}$. The isolated islets were transferred to and cultured in serum free transfection medium $\left(\mathrm{Ca}^{2+}\right.$-containing Krebs-Ringer-HEPES medium) at 2 -d post-isolation, in vitro transfection was conducted as previously described ${ }^{25}$.

Protein isolation and western blotting. The BCA kit was used to determine the protein concentrations. Isolated mouse islets and whole cell lysates of pancreatic $\beta$ cell lines were prepared for western blotting using various primary antibodies, as indicated. Secondary antibodies against rabbit or mouse IgG were used to detect protein signals ${ }^{26}$.

Co-immunoprecipitation. $\quad 1-2 \mu \mathrm{g}$ of antibody was added to the same amount $(400 \mu \mathrm{g})$ of cell lysates overnight at $4^{\circ} \mathrm{C}$. Protein A/G-agarose spheres (Santa Cruz Biotechnology, Dallas, TX, USA) were added and the samples stored at $4^{\circ} \mathrm{C}$ for $2 \mathrm{~h}$. The samples were then centrifuged at $14,000 \times g, 4^{\circ} \mathrm{C}$ for $2 \mathrm{~min}$, washed with lysis buffer three times and boiled for $10 \mathrm{~min}$ after the addition of $20 \mu \mathrm{L} 5 \times$ SDS Loading Buffer. The denatured samples were kept at $-20^{\circ} \mathrm{C}$ for western blotting ${ }^{27}$.

Quantitative real-time reverse transcription polymerase chain reaction (qRT-PCR) analysis. Total RNA was isolated using the Trizol reagent. One microgram of total RNA was converted into first-strand cDNA using a Reverse Transcription Kit. SYBR Green and the 7300 Real-Time PCR system (Applied Biosystems, Carlsbad, CA, USA) were used to carry out the qRT-PCR analysis. PCR cycling conditions included initial denaturation at $95^{\circ} \mathrm{C}$ for $30 \mathrm{~s} ; 40 \mathrm{cycles}$ of denaturation at $95^{\circ} \mathrm{C}$ for $5 \mathrm{~s}$, primer annealing and extension at $60^{\circ} \mathrm{C}$ for $34 \mathrm{~s}$; followed by final extension at $68^{\circ} \mathrm{C}$ for $45 \mathrm{~s}$. $\beta$-actin gene expression was used as an internal standard to calculate the expression levels. The specific primers used are shown in Table S1.

Cell viability. MIN6 cells were seeded in 96-well plates at $1 \times 10^{4}$ cells/well for MTT measurement and then subjected to the indicated treatments. Thereafter, $20 \mu \mathrm{L}$ of $5 \mathrm{mg} / \mathrm{mL}$ MTT was added to each well and incubated for $4 \mathrm{~h}$. The formazan crystals were dissolved in dimethyl sulphoxide after the supernatant was removed. A microplate reader was used to measure the absorbance at $490 \mathrm{~nm}$ to assess the cell viability ${ }^{28}$. 
Cell proliferation assay by 5-ethynyl-2'-deoxyuridine (EdU) labelling. DNA synthesis was analysed using an EdU Labelling Kit. MIN6 cells were cultured in 6-well plates on coverslips. EdU was added to the culture medium $(50 \mu \mathrm{M})$ for $2 \mathrm{~h}$ after treatment and cell proliferation was determined according to the manufacturer's instructions.

Immunofluorescence assay (IFA). IFA was used to observe visually the changes in localization and levels of phospho-STAT3 or the level of Src. MIN6 cells or isolated mouse islets were subjected to IFA after transfection and pharmaceutical treatment. Fluorescein-labelled antibodies diluted in PBS-BSA [anti-insulin/Cy3 antibody (1:50) and anti-phospho-STAT3/TRITC antibody (1:50) or anti-insulin/Cy3 antibody (1:50) and anti-Src/TRITC antibody (1:50)] were added to MIN6 cells or mouse islets and incubated overnight at $4{ }^{\circ} \mathrm{C}$. Isolated mouse islets in suspension were centrifuged at $2000 \times \mathrm{g}$ for $5 \mathrm{~min}$ at $4^{\circ} \mathrm{C}$ at each step ${ }^{23,26}$.

Flow cytometric analysis. A trypsin-EDTA solution was used to digest MIN6 cells. Trypsinised MIN6 cells were collected by centrifugation at $500 \times g$ for $5 \mathrm{~min}$. The MIN6 cell pellets were washed with PBS three times and fixed in cold $75 \%$ ethanol at $4{ }^{\circ} \mathrm{C}$ overnight. Flow cytometry, preceded by propidium iodide (PI) staining, was used to determine the percentages of cells in the G0/G1, S and G2/M phases.

Luciferase reporter assay. According to the manufacturer's instructions, the luciferase reporter construct pGMSTAT3-Lu was transfected transiently into MIN6 cells cultured in 24 well plates, using the Lipofectamine 2000 reagent. The gene encoding $\beta$ galactosidase, expressed in a plasmid driven by the cytomegalovirus (CMV) promoter (Clontech Laboratories, Palo Alto, CA, USA), was transfected simultaneously as an internal control. Six hours after transfection, the medium was replaced. The cells were treated $24 \mathrm{~h}$ after transfection and harvested for luciferase reporter assays, as described previously ${ }^{29}$.

Data analysis. All data were representative of at least three experiments. Results are expressed as the mean \pm SEM. Comparisons were performed using Student's t-test for two groups or ANOVA for multiple groups. $P$ values $<0.05$ were considered statistically significant.

\section{Results}

Src is activated in MIN6 cells. To explore the association of Src with $\beta$-cells mass and T2DM, especially its risk factors such as Glu-palm, LPS and TNF- $\alpha$, MIN6 cells were subjected to different stimuli, such as treatment with $0.4 \mathrm{mM}$ palmitate plus $16.7 \mathrm{mM}$ glucose for $24 \mathrm{~h}$, or $80 \mathrm{nM}$ TNF- $\alpha$ for $6 \mathrm{~h}$, or $10 \mu \mathrm{g} / \mathrm{mL} \mathrm{LPS}$ for $24 \mathrm{~h}$, according to our previous reports ${ }^{28,30}$. The protein levels of Src and p-Src were then assessed by western blotting (Fig. 1A, B,C). The results showed an increase of p-Src in MIN6 cells that were exposed to glucolipotoxicity, or treated with TNF$\alpha$ or LPS $(\mathrm{P}<0.05)$, while the protein level of Src was stable $(\mathrm{P}>0.05)$. Primary islets were isolated from male $\mathrm{db} /$ $\mathrm{db}$ mice (originally bred from C57BL/6J mice) and normal male ICR mice (C57BL/6J). The protein level of p-Src was also increased in primary islets from $\mathrm{db} / \mathrm{db}$ mice compared with the control mice (Fig. $1 \mathrm{D}, \mathrm{P}<0.05$ ), suggesting that Src is activated in vivo in response to glucolipotoxicity. Activated Src in primary islets was also examined using IFA with an anti-p-Src antibody (red fluorescence Fig. 1E). Activated Src was significantly elevated in islets isolated from male $\mathrm{db} / \mathrm{db}$ mice compared with normal male ICR mice (C57BL/6J). An anti-insulin antibody was employed to distinguish islet $\beta$ cells from non- $\beta$ cells in this experiment. The data suggested that Src tyrosine kinases are activated in MIN6 cells in response to risk factors for the development of T2DM.

Proliferation of pancreatic $\beta$ cells is inhibited in rodent models of T2DM. We next investigated whether activated Src is involved in the proliferation of pancreatic $\beta$ cells in response to the stimuli related to T2DM. After exposure of MIN6 cells to glucolipotoxicity ( $0.4 \mathrm{mM}$ palmitate plus $16.7 \mathrm{mM}$ glucose), TNF- $\alpha$ $(80 \mathrm{nM})$ or LPS $(10 \mu \mathrm{g} / \mathrm{mL})$ for $24 \mathrm{~h}^{28,30}$, the percentage of EdU-positive $\beta$ cells decreased compared with the control (Fig. 2A, $\mathrm{P}<0.05$ ). Meanwhile, flow cytometry after PI labelling showed that the percentage of MIN6 cells increased in the $\mathrm{G} 1$ phase (Fig. $2 \mathrm{~B}, \mathrm{P}<0.05$ ), but decreased in the $\mathrm{S}$ phase (Fig. $2 \mathrm{C}, \mathrm{P}<0.05$ ) in response to glucolipotoxicity, TNF- $\alpha$ or LPS. These data indicated that proliferation did not increase after the cells were treated with factors related to T2DM. These factors led to cellular senescence via G1 cell cycle arrest in MIN6 cells. Considering the data in Fig. 1, we hypothesized that activated Src did not improve cell viability and proliferation in MIN6 cells in response to the risk factors of T2DM.

RIG-I is upregulated in rodent models of T2DM. To explore the relationship between the PRR RIG-I and risk factors related to T2DM, cells were exposed to risk factors of T2DM. Additionally, retinoic acid (RA) is a specific agonist of RIG-I. In MIN6 cells exposed to glucolipotoxicity ( $0.4 \mathrm{mM}$ palmitate plus $16.7 \mathrm{mM}$ glucose), LPS $(10 \mu \mathrm{g} / \mathrm{mL})$ or RA $(20 \mu \mathrm{M})$ for $24 \mathrm{~h}$, or transfected with plasmid RIG-I, qRT-PCR analysis indicated that the mRNA level of $R I G-I$ was obviously increased (Fig. $3 \mathrm{~A}, * \mathrm{P}<0.05$ ). Western blotting showed that glucolipotoxicity, LPS, RA or transfection with RIG-I remarkably increased the RIG-I protein levels (Fig. 3B P $<0.05$ ). The mRNA level and protein level of RIG-I were also increased in primary islets from $\mathrm{db} / \mathrm{db}$ mice compared with the corresponding controls (Fig. 3C,D; P $<0.05$ ), suggesting that RIG-I increased in response to in vivo glucolipotoxicity. Meanwhile, RIG-I was also examined by IFA using an anti-RIG-I antibody (red fluorescence, Fig. 3E). RIG-I was increased in cells treated with glucolipotoxicity, LPS, RA or RIG-I-transfection compared with the control group. These data showed that RIG-I was upregulated in rodent models of T2DM, accompanied by activated Src signals.

Elevated RIG-I inhibits proliferation in a pancreatic $\beta$ cell line. Insulin-like growth factor I (IGF-1) was reported to induce cell proliferation, and is closely associated with Src activity ${ }^{31}$. To explore the role of RIG-I in Src signalling and cell proliferation in pancreatic $\beta$ cells, we performed a series of experiments using IGF-1 
A

WB Control Glucolipotoxicity

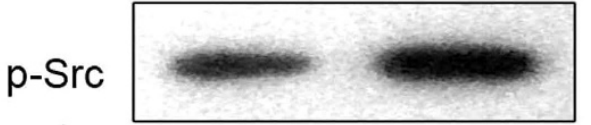

Src

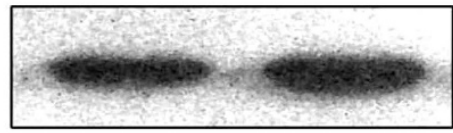

$\beta$-actin

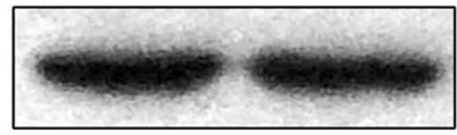

C

WB

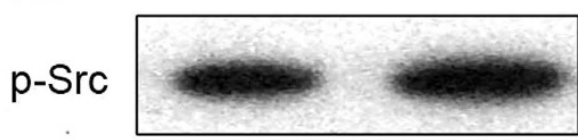

Src

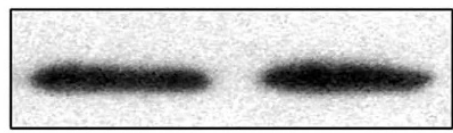

$\beta$-actin

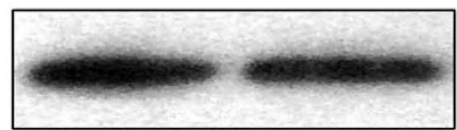

E
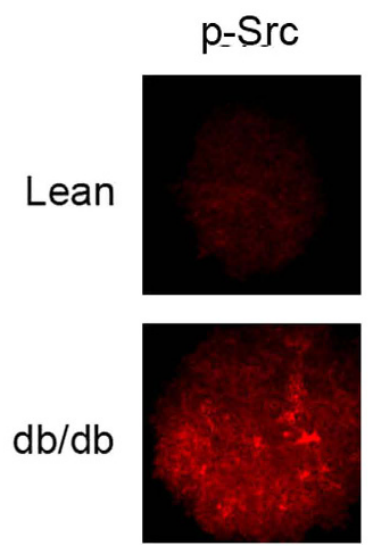

\section{Insulin}
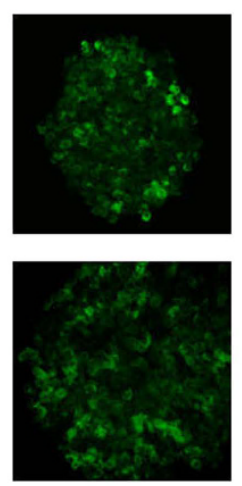

B

WB $\mathrm{p}-\mathrm{Src}$ Control TNFa

Src

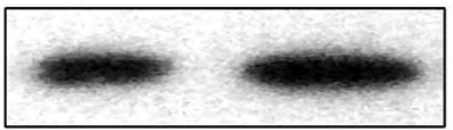

$\beta$-actin
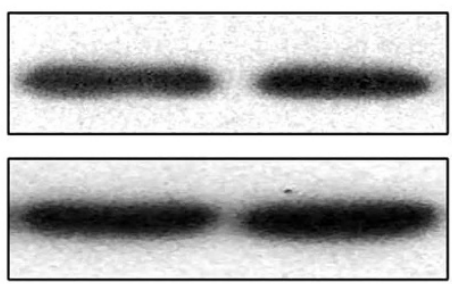

D

WB

Lean

$\mathrm{db} / \mathrm{db}$

p-Src

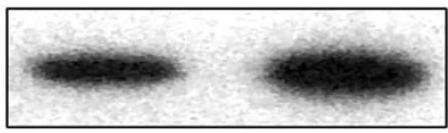

Src

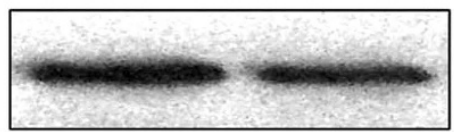

$\beta$-actin

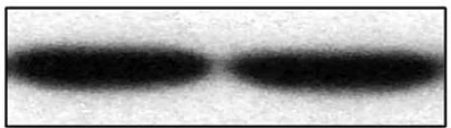

Figure 1. Src is activated in rodent models of type 2 diabetes. Min6 cells were treated with: (A) glucolipotoxicity (glucose $16.7 \mathrm{mM}$ and $0.4 \mathrm{mM}$ palmitate) for $24 \mathrm{~h}$; (B) TNF- $\alpha$ ( $80 \mathrm{nM}$ ) for $6 \mathrm{~h}$; or (C) LPS $(10 \mu \mathrm{g} / \mathrm{mL})$ for $24 \mathrm{~h}$, and cell extracts were collected. (D) Isolated islets from ICR or $\mathrm{db} / \mathrm{db}$ mice. Cell extracts were analysed by western blotting using antibodies against p-Src (Tyr416) and Src. $\beta$-actin was detected as an internal control. (E) Islets were isolated from ICR or $\mathrm{db} / \mathrm{db}$ mice. IFA was performed with antibodies directed against p-Src (red) and insulin (green). Insulin with green staining was used to identify $\beta$ cells (scale bar $=100 \mu$ $\mathrm{m})$. Data are means $\pm \mathrm{SEM}$ of three separate experiments.

treatment. RA, a RIG-I specific agonist, was used in the experiment at different concentrations $(0,1,5,10,20$, 50 and $100 \mu \mathrm{M})$ for different times $(6,12$ and $24 \mathrm{~h})$ with IGF-1 $(10 \mathrm{nM})^{28}$ to investigate the role of RIG-I in the pancreatic $\beta$ cell line. MTT assays indicated that RA at more than $5 \mu \mathrm{M}$ inhibited the viability of MIN6 cells in a dose-dependent manner (Fig. 4A). We then investigated whether RIG-I could inhibit the proliferation of pancreatic $\beta$ cells. MIN6 cells were subjected to starvation for $24 \mathrm{~h}$ in medium depleted of amino acids and serum, followed by IGF-I treatment in serum-free medium ${ }^{28}$, and then treated with RA $(10 \mu \mathrm{M})$ or transfected with plasmid RIG-I. The percentage of EdU-positive $\beta$ cells increased in the cells treated with IGF- 1 only, while the percentage 


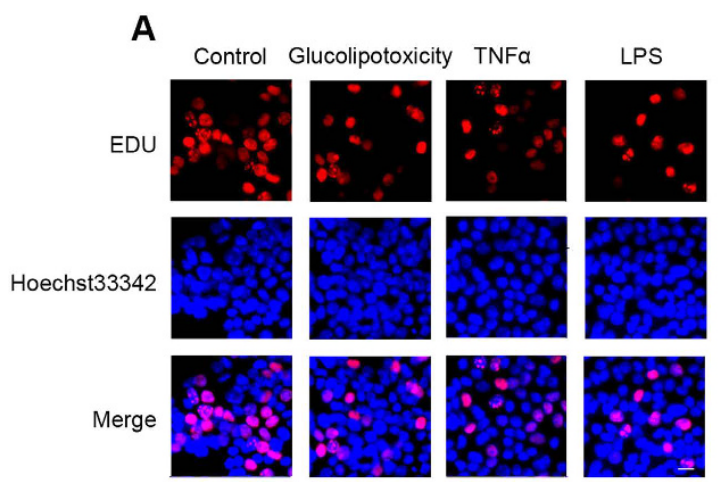

B

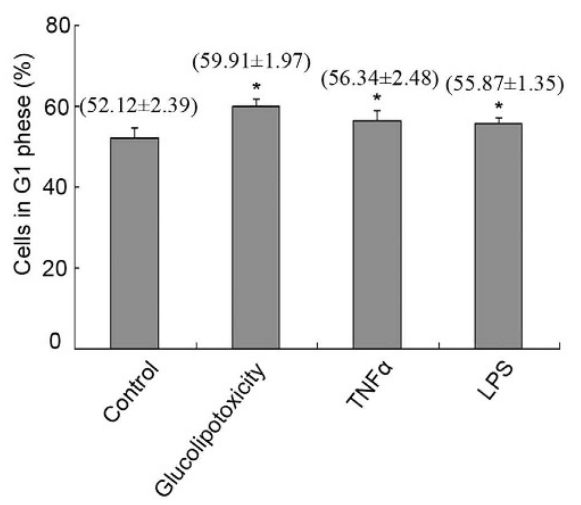

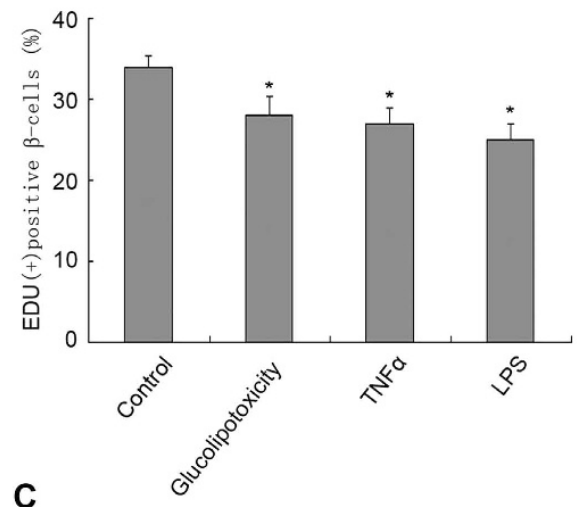

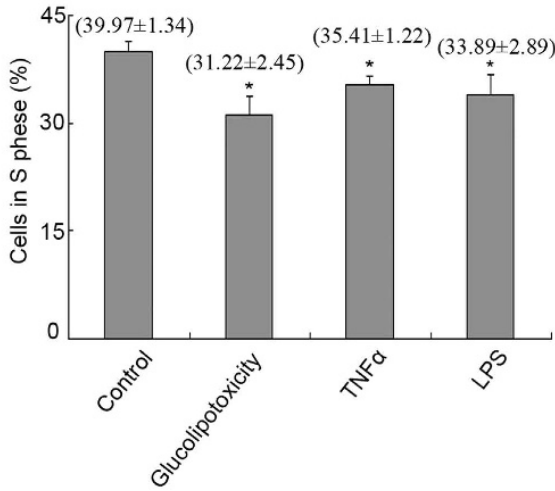

Figure 2. Proliferation of pancreatic $\boldsymbol{\beta}$ cells is inhibited in rodent models of type 2 diabetes. Min 6 cells were stimulated with glucolipotoxicity, TNF- $\alpha$ and LPS for $24 \mathrm{~h}$, as indicated in Fig. 1. (A) DNA synthesis was analysed using EdU labelling assays. Representative micrographs of EdU labelling assays in MIN6 cells are shown $($ scale bar $=120 \mu \mathrm{m})$. The percentage of EdU-positive $\beta$ cells was quantified. Flow cytometric assays were performed to determine the percentages of MIN6 cells at the (B) G1 phase and (C) S phase. Data are means $\pm \mathrm{SEM}$ of three separate experiments. $* \mathrm{P}<0.05$ versus control.

of EdU-positive $\beta$ cells decreased in the cells treated with IGF-1 and RA or in those transfected with plasmid RIG-I (Fig. 4B, P $<0.05$ ). Flow cytometric assays after PI labelling showed that the percentage of MIN6 cells increased in the $\mathrm{G} 1$ phase (Fig. $4 \mathrm{C}, \mathrm{P}<0.05$ ), but decreased in the $\mathrm{S}$ phase in response to RA treatment or RIG-I plasmid transfection (Fig. 4D, $\mathrm{P}<0.05$ ). To explore whether RIG-I affects the proliferation of $\beta$ cells, we used a small interfering RNA, si-RIG-I RNA, to transfect MIN6 cells. The percentage of EdU-positive cells increased in cells transfected by si-RIG-I RNA and treated with RA compared with cells transfected with a scrambled siRNA (Fig. 4E, $\mathrm{P}<0.05$ ). These results suggested that RIG-I contributes to the inhibition of proliferation elicited by IGF/ Src signalling in MIN6 cells.

Elevated RIG-I inhibits proliferation via stabilization of P27 in pancreatic $\beta$ cell line. Elevated RIG-I inhibits Src-induced proliferation and the phenomenon is associated with the cell cycle. Thus, cyclin D1, cyclin E, CDK2, P27Kip1 and p21 were analysed at the mRNA and protein levels. MIN6 cells were subjected to starvation for $24 \mathrm{~h}$ in medium depleted of amino acids and serum, followed by IGF-I treatment in serum-free medium. Cells were transfected with plasmid RIG-I or treated with RA. QRT-PCR analysis indicated that the cyclin D1 and cyclin E mRNAs decreased slightly and CDK2, p27 and p21 mRNA levels remained stable (Fig. 5A, $\mathrm{P}>0.05)$. Meanwhile, western blotting showed that RIG-I transfection induced a decrease in cyclin E protein levels and increased P27 levels (Fig. 5B,C, P < 0.05), whereas other protein levels were unaffected $(\mathrm{P}>0.05)$. To explore the possible involvement of the RIG-I pathway in $\beta$-cells upon IGF-induced downregulation of P27 protein levels, MG132, a specific inhibitor of the proteasome, was used a subsequent experiment. MG132 remarkably upregulated the protein levels of P27Kip1 in response to IGF stimuli (Fig. 5D, P $<0.05$ ), but did not affect the change of P27Kip1 when RIG-I was elevated (Fig. 5D, P > 0.05). These data suggested that RIG-I-induced accumulation of P27Kip1 might be attributed to increased stability of P27 and impairment of ubiquitin-dependent proteasome degradation of this protein.

RIG-I induced downregulation of Skp2, which is involved in the stability of P27 in pancreatic $\beta$ cells. The periodicity of P27 depends on ubiquitin degradation, and the specificity of ubiquitination is provided by the E3 ligases. Skp2 is an E3 ligase that targets P27. To confirm whether Skp2 is involved in this process, IGF-1, RA 
A

B

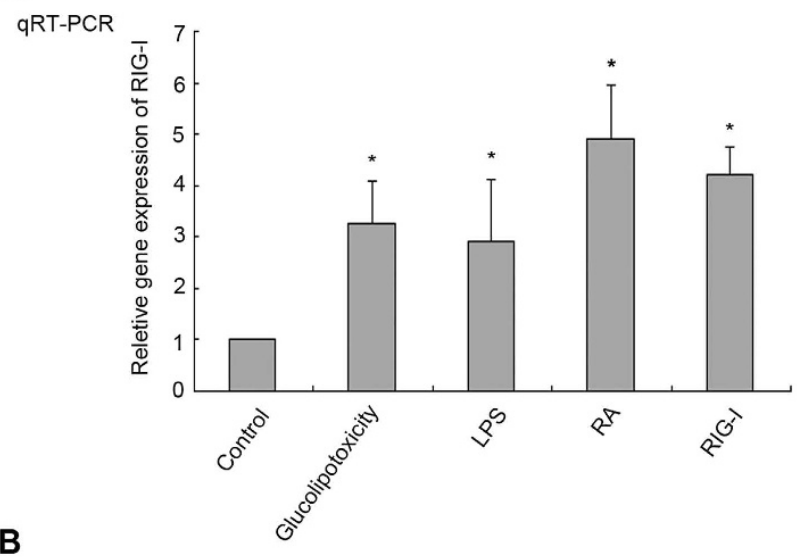

WB

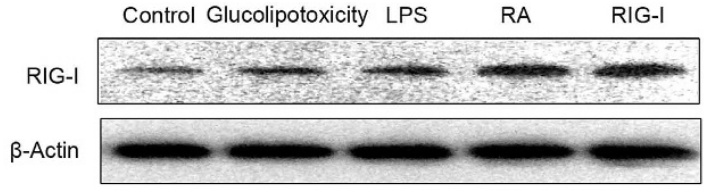

C

QRT-PCR

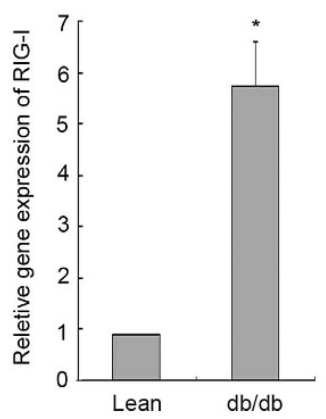

D

WB

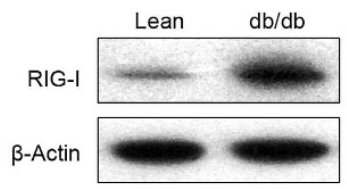

E
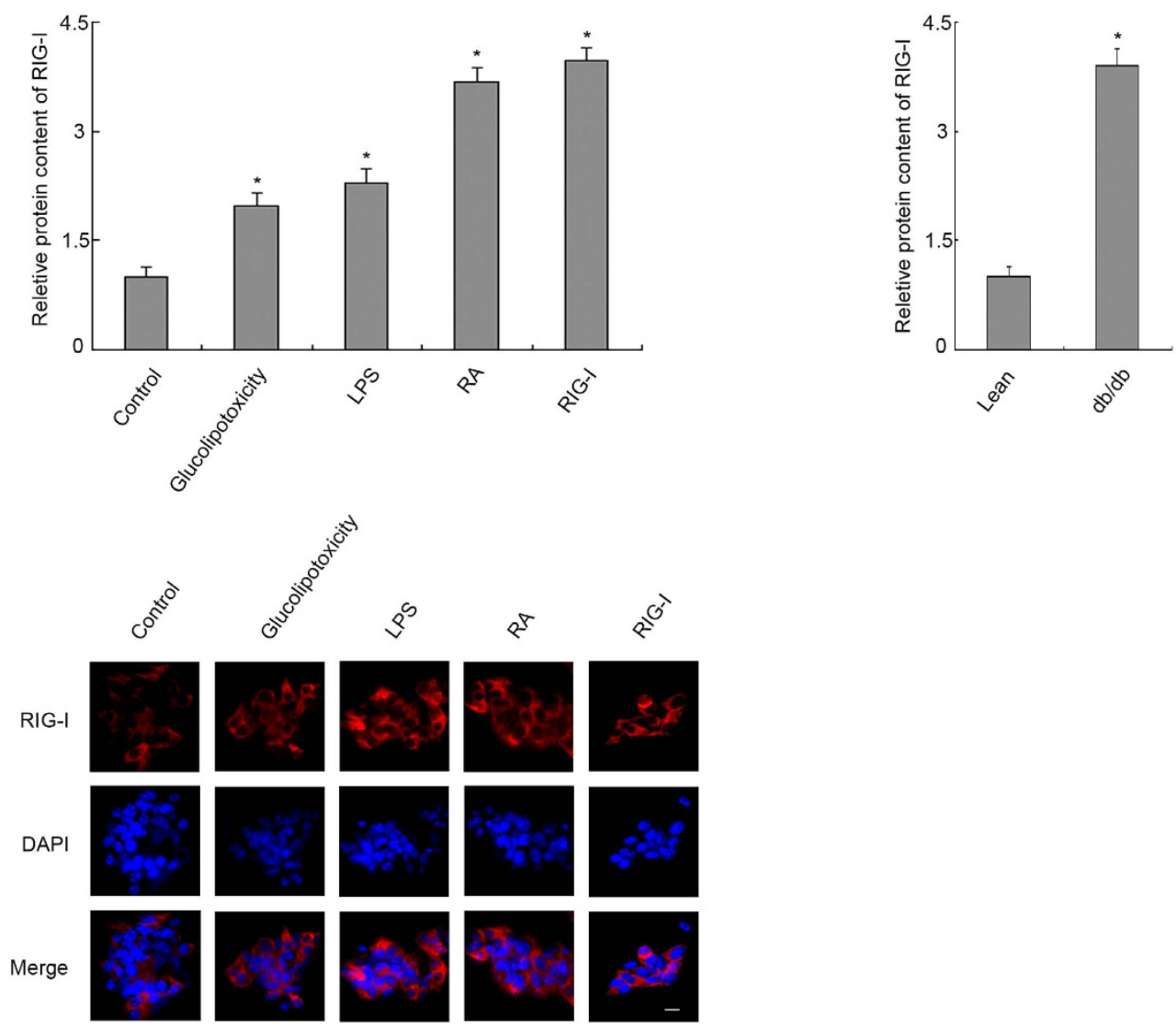

Figure 3. RIG-I is upregulated in MIN6 cells. Min6 cells were stimulated with glucolipotoxicity, LPS or retinoic acid (RA) $(10 \mu \mathrm{M})$, or transfected with a plasmid encoding $R I G-I$ for $24 \mathrm{~h}$, as indicated, and cell extracts were collected. (A) QRT-PCR to detect the mRNA levels of RIG-I in Min6 cells. (B) Cell extracts were analysed by western blotting using antibodies against RIG-I. Islets were isolated from ICR or db/db mice. (C) QRT-PCR analysis and (D) western blotting were performed to detect the mRNA or protein levels of RIG-I in primary cells. Quantification of the relative protein content of RIG-I is shown. $\beta$-actin was detected as an internal control. (E) Min6 cells were treated with glucolipotoxicity, LPS or RA or transfected with a plasmid encoding RIG-I for $24 \mathrm{~h}$, as indicated. IFA was performed with antibodies against RIG-I (red); DAPI was used for nuclear staining (blue) $($ scale bar $=120 \mu \mathrm{m})$. Data are means \pm SEM of three separate experiments. $* \mathrm{P}<0.05$ versus control. 
A
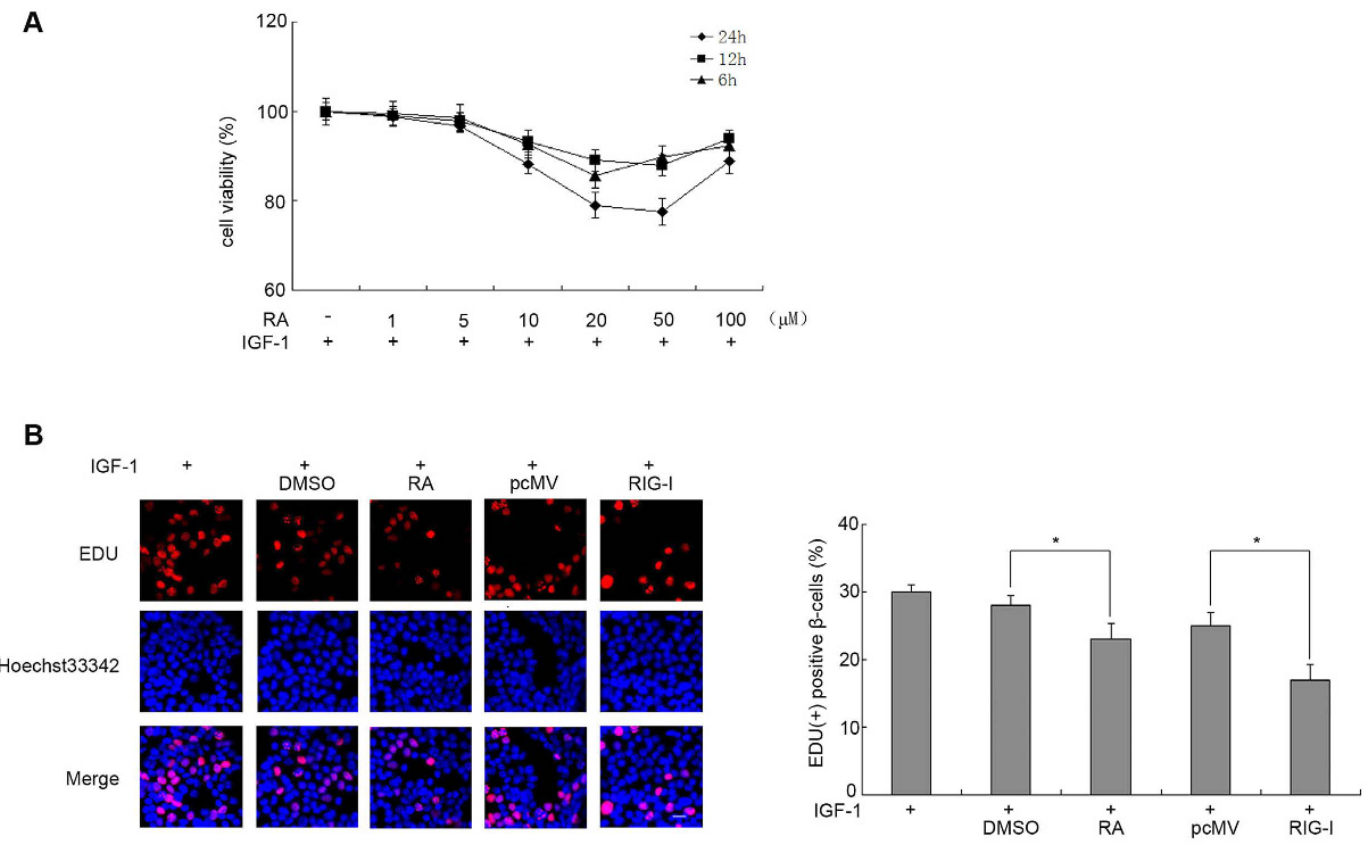

C

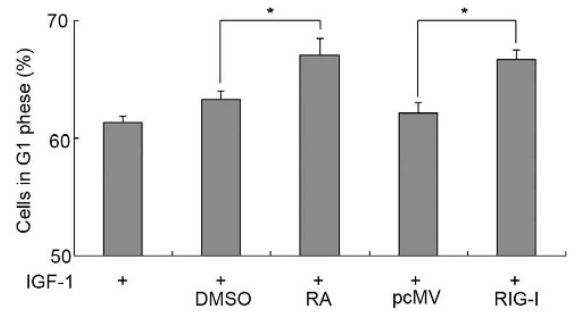

D

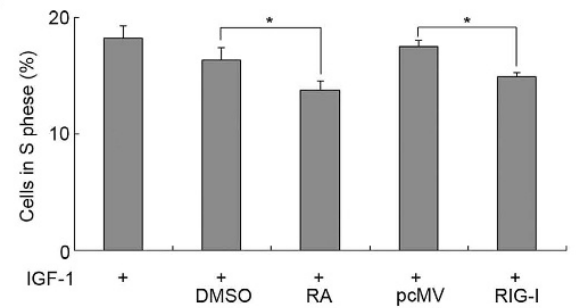

$\mathbf{E}$
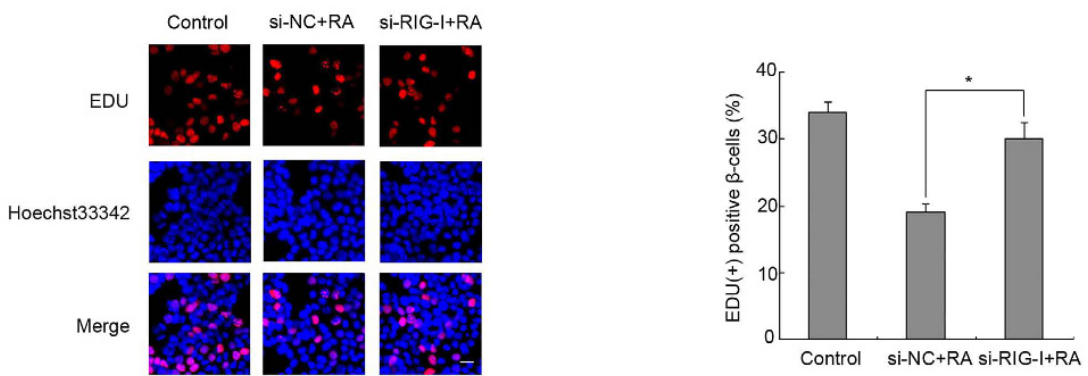

Figure 4. Elevated RIG-I inhibits proliferation in pancreatic $\beta$ cell line. (A) Min 6 cells were treated with the indicated concentrations $(0,1,5,10,20,50$ and $100 \mu \mathrm{M})$ of retinoic acid (RA) for the indicated times $(6 \mathrm{~h}, 12 \mathrm{~h}$ and $24 \mathrm{~h})$ and stimulated with IGF-1 (10 nM). Cell viability was assessed by the MTT assay. 24 hours after transfection of a plasmid encoding RIG-I, Min6 cells were treated with IGF-1 and RA as indicated. (B) DNA synthesis was analysed using EdU labelling assays. Representative micrographs of EdU labelling assays in MIN6 cells are shown $($ scale bar $=120 \mu \mathrm{m})$. The percentage of EdU-positive $\beta$ cells was quantified. Flow cytometric assays were performed to calculate the percentages of MIN6 cells at the (C) G1 phase and (D) S phase. (E) After transfection of si-RIG-I for $24 \mathrm{~h}$, Min6 cells were treated with RA. DNA synthesis was analysed using EdU labelling assays. Representative micrographs of EdU labelling assays in MIN6 cells are shown (scale bar $=120 \mu \mathrm{m}$ ). The percentage of EdU-positive $\beta$ cells was quantified. Data are means \pm SEM of three separate experiments. $* \mathrm{P}<0.05$ versus control.

and plasmid with RIG-I were used to treat MIN6 cells. QRT-PCR and western blotting analyses showed that the SKP2 mRNA and protein levels were reduced (Fig. 6A,B) after MIN6 cells were treated with RA or transfected with the RIG-I plasmid, which were significantly different to cells treated with IGF-1 only $(\mathrm{P}<0.05)$. To explore the role of Skp2 in P27 protein stability, MIN6 cells were transfected with a SKP2 plasmid. SKP2 overexpression 
A

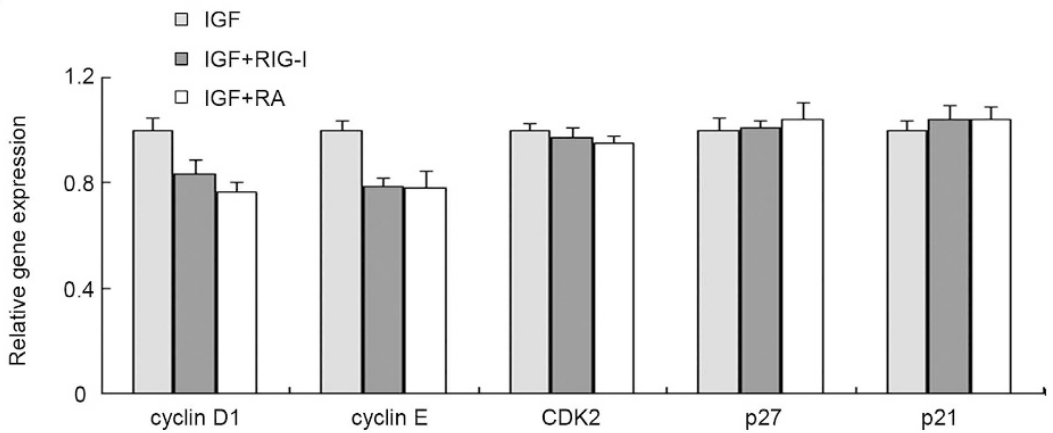

B
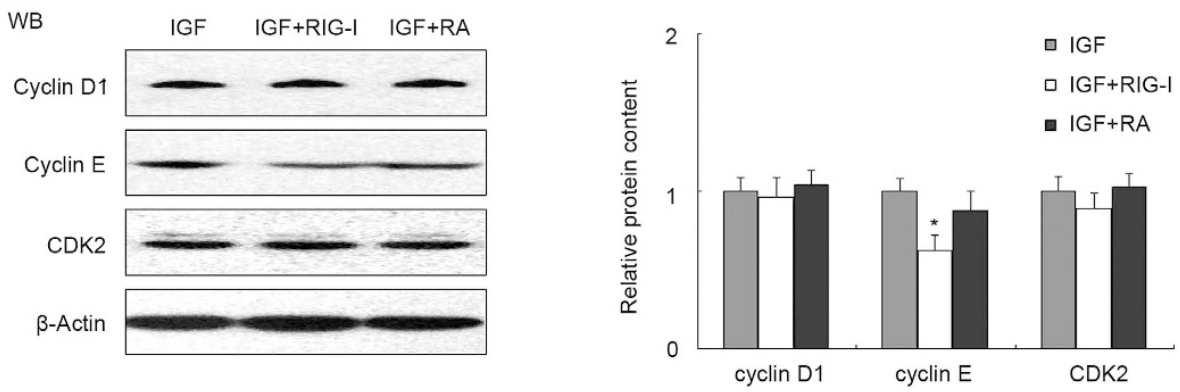

C
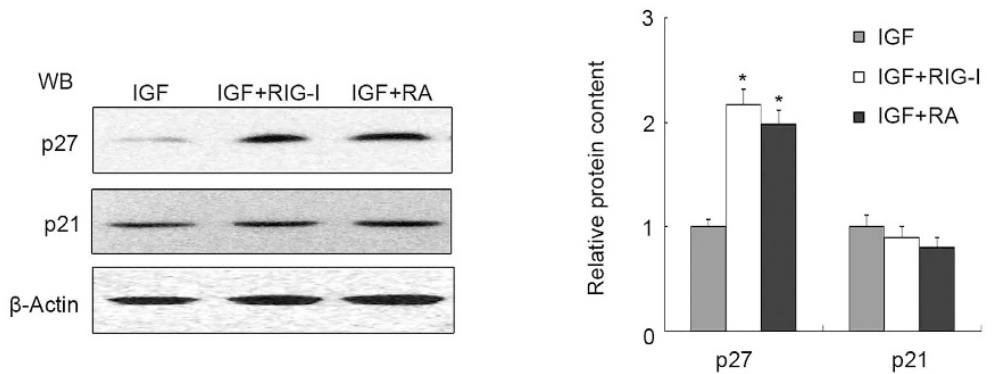

D
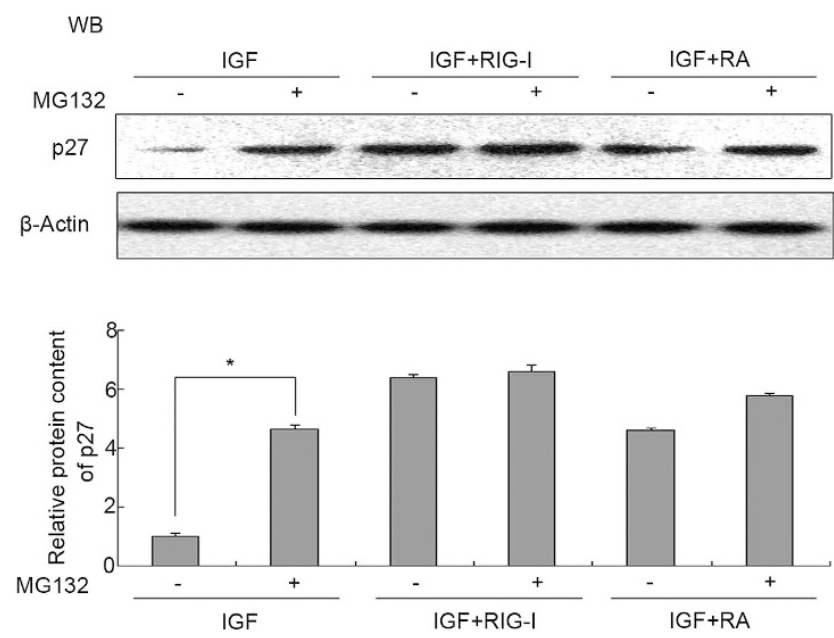

Figure 5. Elevated RIG-I inhibits proliferation via stability of p27 in pancreatic $\beta$ cell line. $24 \mathrm{~h}$ after transfection of a plasmid encoding RIG-I, Min6 cells were treated with IGF-1 and RA, as indicated. (A) The mRNA levels of the indicated genes, including those encoding positive cell cycle regulators cyclin D1, cyclin E, CDK2, and negative regulators p 21 and p27, were determined by qRT-PCR. Cell extracts were analysed by western blotting with antibodies against $(\mathbf{B})$ positive and $(\mathbf{C})$ negative cell cycle regulators. (D) MIN6 cells were pre-treated with or without MG132 $(20 \mu \mathrm{M})$ for $1 \mathrm{~h}$ and subsequently treated as indicated. Cell extracts were analysed by western blotting with antibodies against P27. $\beta$-actin was detected as an internal control. Data are means \pm SEM of three separate experiments. $* \mathrm{P}<0.05$ versus control. 
A

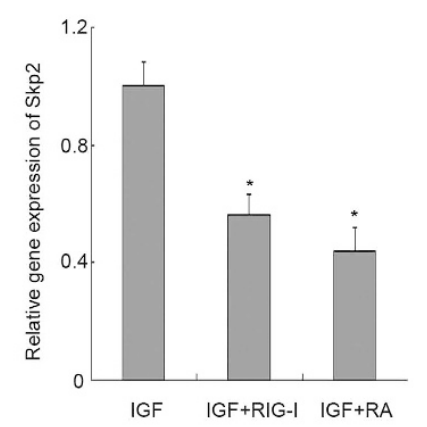

C

WB
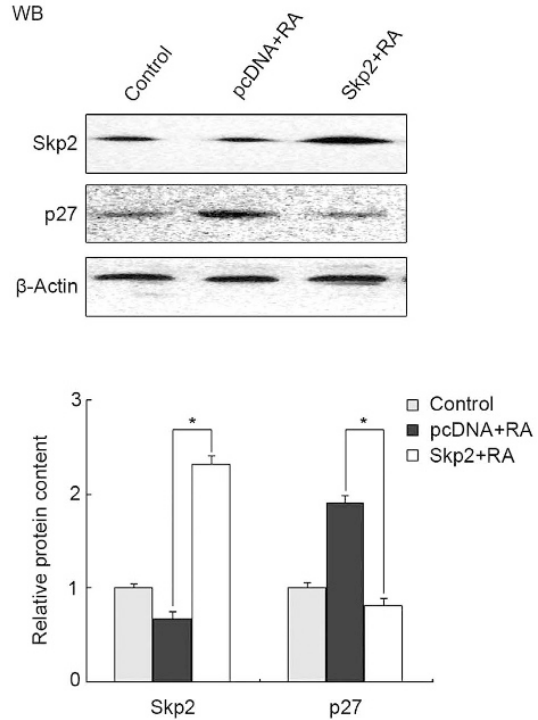

B

WB
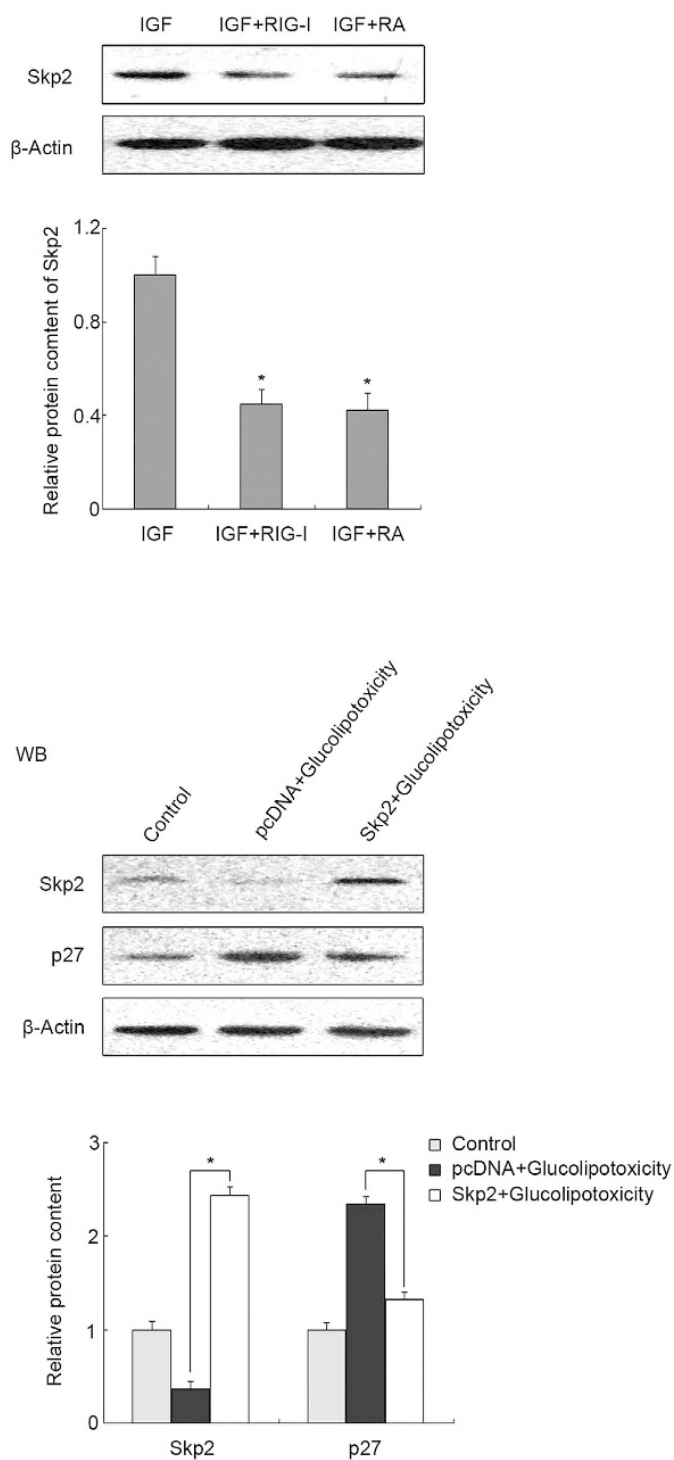

Figure 6. RIG-I-induced downregulation of Skp2 is involved in the stability of P27 in a pancreatic $\beta$ cell line. $24 \mathrm{~h}$ after transfection of plasmid encoding RIG-I, Min6 cells were treated with IGF-1 and RA, as indicated in the above experiments. (A) The mRNA and (B) protein levels of $S k p 2$ were determined by qRTPCR and western blotting, respectively. Min6 cells were transfected with a plasmid encoding $S k p 2$ for $24 \mathrm{~h}$ and subsequently treated with (C) RA or (D) glucolipotoxicity, as indicated. Cell extracts were analysed by western blotting with antibodies against Skp2 and P27. $\beta$-actin was detected as an internal control. Data are means \pm SEM of three separate experiments. $* \mathrm{P}<0.05$ versus control.

reversed RA-induced upregulation of P27 protein levels (Fig. 6C, P $<0.05$ ), suggesting that RIG-I regulates P27's function through Skp2-induced protein degradation. Glucolipotoxicity is involved in the increment of RIG-I protein levels and proliferation inhibition of pancreatic $\beta$-cells; therefore, to explore the molecular mechanisms underlying role of RIG-I in glucolipotoxicity-induced proliferation inhibition, MIN6 cells were treated using $0.4 \mathrm{mM}$ palmitate plus $16.7 \mathrm{mM}$ glucose. The Skp2 protein level decreased and P27 protein level increased in response to glucolipotoxicity. Skp2 overexpression could reverse the increment in the P27 protein level elicited by glucolipotoxicity (Fig. 6D, $\mathrm{P}<0.05$ ). These data indicated that RIG-I induced downregulation of the Skp2 protein level, resulting in increased stability of P27, which might be associated closely with glucolipotoxicity.

STAT3 increased the expression of Skp2 in a pancreatic $\beta$ cell line. RIG-I affected the expression of SKP2 mRNA level. Previous literature showed that STAT3 might induce Skp2 expression ${ }^{32}$; therefore, to explore 
A

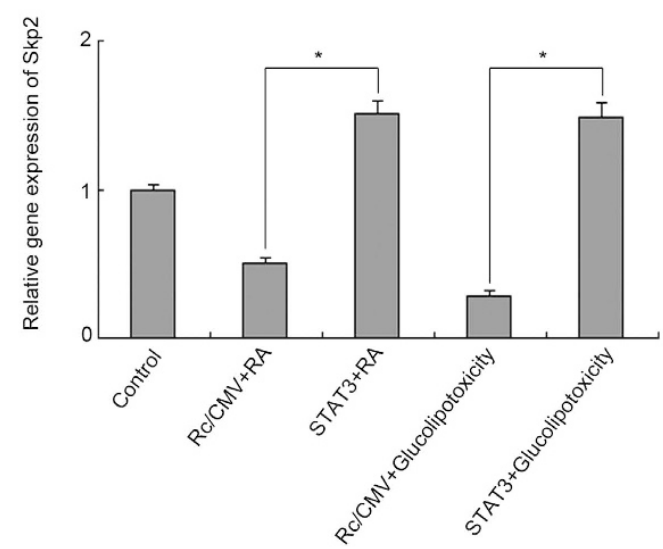

B

WB
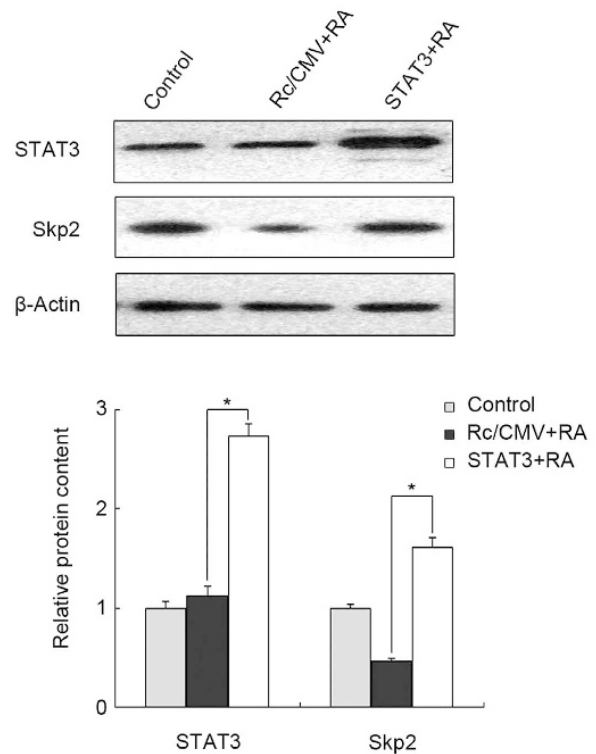

C
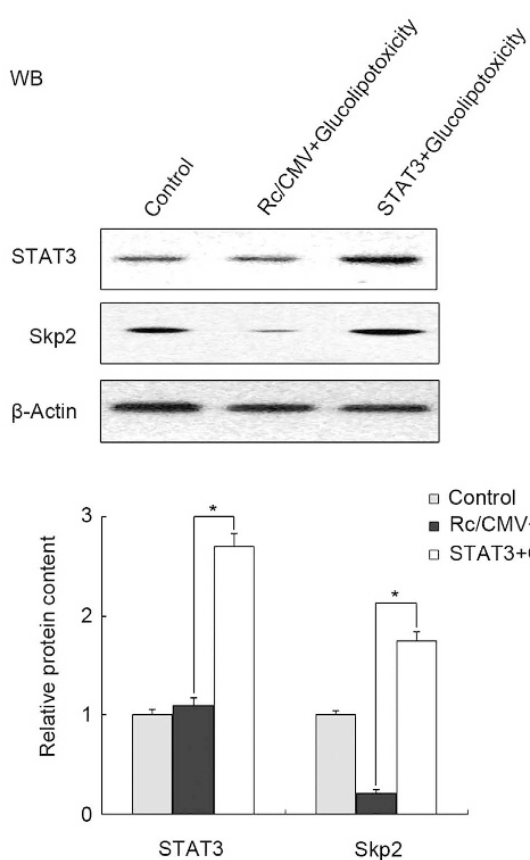

Figure 7. STAT3 increased the expression of Skp2 in pancreatic $\beta$ cell line. Min 6 cells were transfected with a plasmid encoding STAT3 for $24 \mathrm{~h}$ and subsequently treated with RA or glucolipotoxicity, as indicated. (A) The mRNA level of $S k p 2$ was determined by qRT-PCR. Min 6 cells were transfected with plasmid encoding $S k p 2$ for $24 \mathrm{~h}$ and subsequently treated with (B) RA or (C) glucolipotoxicity, as indicated. Cell extracts were analysed by western blotting with antibodies against STAT3 and Skp2. $\beta$-actin was detected as an internal control. Data are means \pm SEM of three separate experiments. $* \mathrm{P}<0.05$ versus control.

the mechanism underlying altered SKP2 transcription, we used plasmid STAT3 to transfect MIN6 cells. After transfection, RA or glucolipotoxicity were used to stimulate the cells. QRT-PCR and western blotting analyses showed that STAT3 overexpression could reverse the RA-induced downregulation of SKP2 mRNA and protein levels (Fig. 7A,B, P $<0.05$ ), suggesting that STAT3 is involved in the regulation of SKP2 transcription. To explore the molecular mechanisms underlying the role of STAT3 in glucolipotoxicity-induced dysfunction of pancreatic $\beta$-cells, MIN6 cells were treated using $0.4 \mathrm{mM}$ palmitate plus $16.7 \mathrm{mM}$ glucose. STAT3 overexpression reversed the reduced mRNA and protein levels of Skp2 in response to glucolipotoxicity (Fig. 7A,C, P $<0.05$ ). These data suggested that STAT3 could be an important regulator controlling SKP2 gene expression in pancreatic $\beta$-cells.

Transcriptional activity of STAT3 was suppressed by RIG-I accumulation. STAT3 contains an Src homology 2 (SH2) domain that is activated by tyrosine phosphorylation in response to a wide variety of cytokines and growth factors ${ }^{33}$. To explore the relationship between STAT3 and factors that influence Src signals, cells were subjected to different treatments. We used si-RIG-I to transfect MIN6 cells and treated the cells with RA. The protein level of p-STAT3 decreased after the cells were treated with RA only, and si-RIG-I plasmid transfection reversed the decrease (Fig. 8A, P $<0.05$ ). We then used IGF-1 to treat MIN6 cells grown in serum-free DMEM. 
A

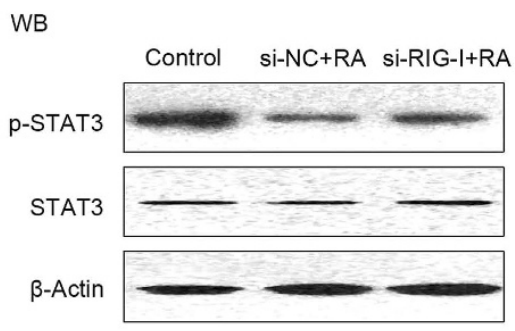

B

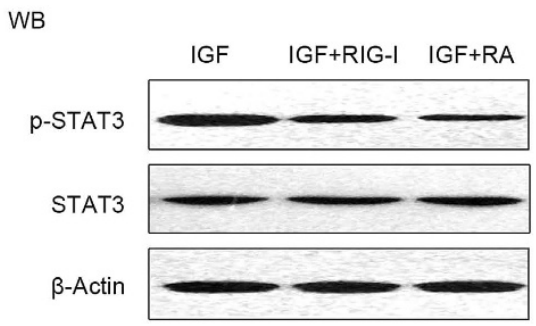

C

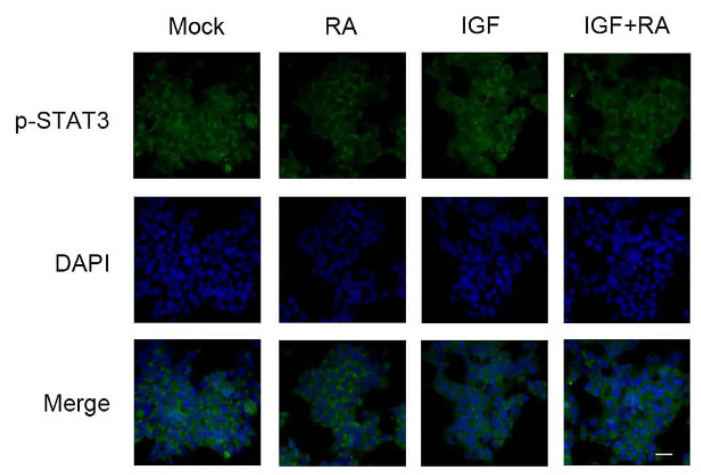

$\mathbf{E}$

WB

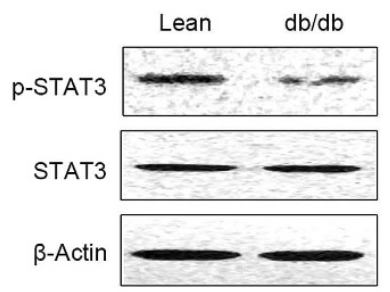

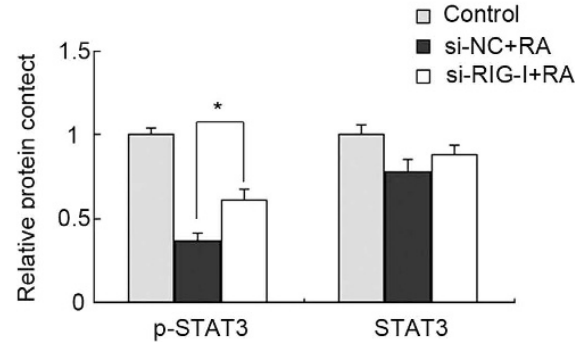

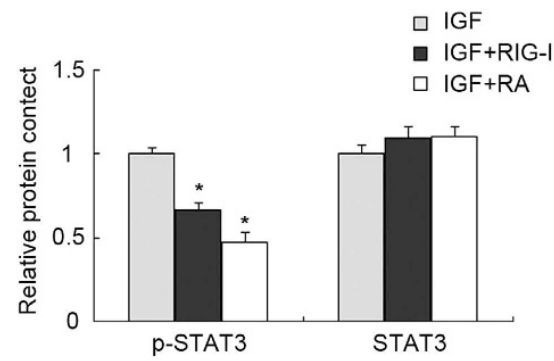

D
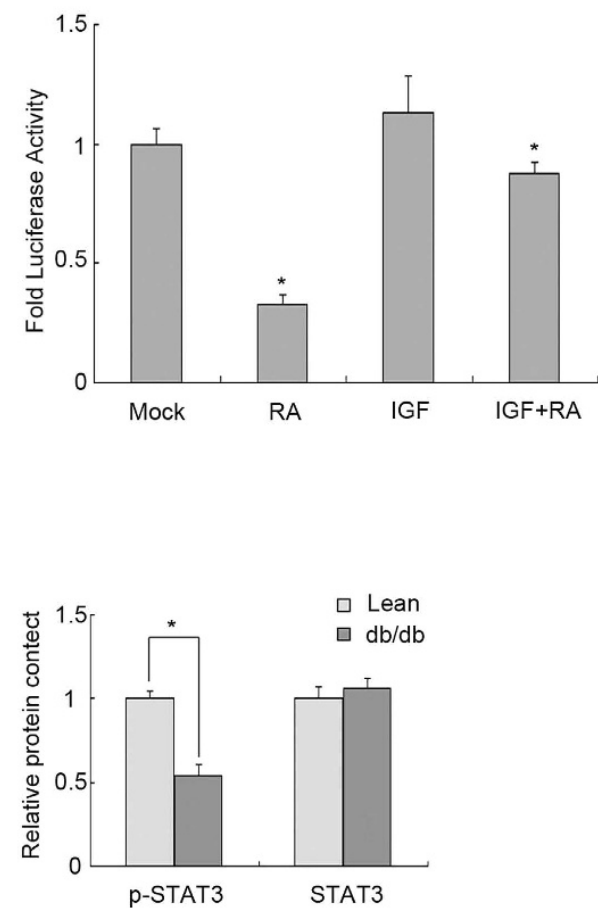

Figure 8. Transcriptional activity of STAT3 was suppressed by RIG-I accumulation. (A) Min6 cells were transfected with si-RIG-I for $24 \mathrm{~h}$, and then treated with RA. Protein levels of p-STAT3 and STAT3 were determined by western blotting. (B) $24 \mathrm{~h}$ after transfection of a plasmid encoding RIG-I, Min 6 cells were treated with IGF-1 and RA, as indicated. Western blotting was used to detect the protein levels of p-STAT3 and STAT3. (C) Min6 cells were treated with IGF-1 or RA, as indicated. IFA was performed with an antibody against p-STAT3 (green); DAPI was used for nuclear staining (blue) (scale bar $=100 \mu \mathrm{m}$ ). (D) Luciferase activity of pGMSTAT3-Lu (a STAT3-dependent reporter) was measured and shown as the fold change. (E) Islets were isolated from ICR or db/db mice. Protein levels of p-STAT3 and STAT3 were determined by western blotting in primary islet cells. $\beta$-actin was detected as an internal control. Data are means \pm SEM of three separate experiments. $* \mathrm{P}<0.05$ versus control. 
Plasmid RIG-I and RA were used to treat the cells. The protein level of p-STAT3 was inhibited more in cells treated with IGF-1 and RA or transfected with plasmid RIG-I compared with IGF-1 treatment only (Fig. 8B, $\mathrm{P}<0.05$ ). Using IFA with an anti-p-STAT3 antibody (green fluorescence Fig. 8C), p-STAT3 was observed to be increased significantly in the nucleus when treated with IGF-1 compared with the mock group grown in serum-free DMEM; however, it was reduced in cell nucleus when treated with RA. To explore the STAT3 transcription activity, MIN6 cells were transfected with a STAT3-dependent reporter construct pGMSTAT3-Lu and then treated as in Fig. 8B. Compared with the mock group or IGF-1 treatment, the luciferase activity was reduced significantly in the group subjected to RA (Fig. $8 \mathrm{D}, \mathrm{P}<0.05$ ). The protein level of p-STAT3 was also decreased in primary islets from $\mathrm{db} / \mathrm{db}$ mice compared with the corresponding control (Fig. $8 \mathrm{E}, \mathrm{P}<0.05$ ), suggesting that STAT3 is activated in response to in vivo glucolipotoxicity. These data indicated that RIG-I was involved in the transcriptional activity of STAT3 in a phosphorylation-dependent manner.

RIG-I interrupts the binding between Src and STAT3. STAT3 is the downstream substrate of Src and binds to its $\mathrm{SH} 2$ domain corresponding sites. Src induces STAT3 dimerization and entry into the nucleus, resulting in the activation of the transcription and translation of target genes. To explore role of RIG-I in its competitive binding with Src and inhibition of Src activity ${ }^{34}$, MIN6 cells were grown in serum-free DMEM and treated with IGF. Western blotting was performed to detect binding of RIG-I and STAT3 with activated Src after co-immunoprecipitation with specific p-Src antibodies. After RIG-I transfection or RA treatment, binding of active Src with RIG-I increased, while binding of active Src with STAT3 was attenuated (Fig. 9A, P <0.05). To investigate whether RIG-I modulated the Src and STAT3 interaction, the si-RIG-I plasmid was used in addition to RA treatment. Binding of active Src with STAT3 was increased compared to RA use only (Fig. 9B, P $<0.05$ ). Furthermore, the STAT3 plasmid was also used to confirm these observations. Binding of active Src with RIG-I was inhibited and binding of active Src with STAT3 was not decreased after transfection with the STAT3 plasmid and treatment with RA compared with treatment with RA only (Fig. 9C, $\mathrm{P}<0.05$ ). Interestingly, the total Src level was not altered in these three experiments. EdU experiments were also carried out. Transfection with plasmid STAT3 could reverse the decrease in the percentage of EdU-positive $\beta$ cells induced by RA (Fig. 9D, P $<0.05$ ). These results suggested that RIG-I inhibits the Src/STAT3 association via competitive binding with active Src, leading to inhibition of pancreatic $\beta$ cells proliferation.

\section{Discussion}

As a metabolic disease, T2DM is characterized by insulin secreted from pancreatic $\beta$ cells that cannot meet the demands of insulin sensitivity or insulin resistance, which might result from over-nutrition with chronic hyperglycaemia and hyperlipidaemia. In the state of excess nutrition, proliferative modulator Src is activated in diabetic islets $^{35,36}$, which was confirmed by our data (Fig. 1 ). However, such a state did not promote $\beta$-cell proliferation, and did not increase the compensatory function (Fig. 2). Perhaps in the initial stage of over-nutrition, activated Src exerts a positive effect on $\beta$ cell growth; however, with development of glucolipotoxicity and metaflammation, Src signalling is impaired by other negative modulators.

The two systems of metabolism and immunity are so integrated that more and more pattern recognition receptors are being identified to play important roles in metabolic disorders ${ }^{37}$. For example, activated PKR and elevated TLR3 upon glucolipotoxicity and pro-inflammatory cytokines stimuli both inhibit $\beta$ cell proliferation to downregulate their functions, leading to failure of $\beta$ cell compensation in the progression of type 2 diabetes ${ }^{23,28,38}$. RIG-I is another PRR thatthat is present in islet $\beta$ cells. As shown in Fig. 3, RIG-I was significantly upregulated in the models of T2DM. Previous studies indicated that TNF- $\alpha$, a cytokine that regulates innate immune responses, induced the expression of RIG-I in endothelial cells. The ability of TNF- $\alpha$ to upregulate RIG-I required protein synthesis, expression of functional type I IFNRs, and STAT1 signalling ${ }^{39}$. Hyperglycaemia causes oxidative stress in pancreatic beta cells of T2DM ${ }^{40}$. ROS might enhance RIG-I levels in pancreatic beta cells ${ }^{41}$. Thus, it necessary to determine whether Rig-I is a negative regulator involved in Src signals and $\beta$-cell proliferation.

Before exploring the potential association between RIG-I and Src-induced proliferation in pancreatic $\beta$ cells, we obtained insights into the effect of RIG-I on $\beta$ cell growth. Previous reports suggested that RIG-I mediated $\beta$ cell lesions ${ }^{42}$; we showed that elevated RIG-I decreased $\beta$ cell viability and abrogated IGF-stimulated proliferation through cycle arrest at the G1 phase. By contrast, knockdown of RIG-I could alleviate RA-mediated proliferation inhibition (Fig. 4). The results revealed that RIG-I is involved in inhibition of $\beta$-cells proliferation elicited by IGF-Src signals.

Recent studies have established that RIG-I restrains myeloid progenitor proliferation through competitive binding with active $\mathrm{Src}^{4}$. The recognition between RIG-I and Src acts through a cooperative interaction involving RIG-I recruitment domains (CARDs) and the Src SH1 domain. In inactive Src, the SH1 domain faces inward and is inaccessible to outside factors; therefore, the RIG-I CARDs preferentially associates with activated Src with an exposed SH1 domain. C-terminal to the RIG-I CARDs there is a classic PxxP motif. The PxxP motif can combine with the Src SH3 domain to prevent activated Src from inducing proliferation. Consistent with this finding,our results suggested that RIG-I could bind active Src competitively to inhibit pancreatic $\beta$ cells proliferation elicited by IGF-Src signals (Figs 4 and 8 ).

RIG-I levels seemed to correlate with augmented $\beta$ cells at G1 phase and reduced levels at $S$ phase in a pancreatic $\beta$-cell line (Fig. 2), which was associated with several cell cycle modulators, such as cyclin D, P21, P27 and P53. In our experiments, accumulated RIG-I increased the protein level of P27, but there was no change at the mRNA level, suggesting post-translational regulation. Additionally, we found that MG132 could reverse significantly the decline of P27 in $\beta$ cells without RIG-I function (Fig. 5). This evidence indicated that RIG-I-induced accumulation of P27 could be attributed to impaired ubiquitin-dependent proteasome degradation of P27. A similar mechanism underlying the degradation of P27 has been reported previously. For example, Prasad et al. demonstrated cytoplasmic P27 accumulation after treatment with MG132 in primary cervical cancer samples and cervical cancer-derived cell lines ${ }^{43}$. 
A
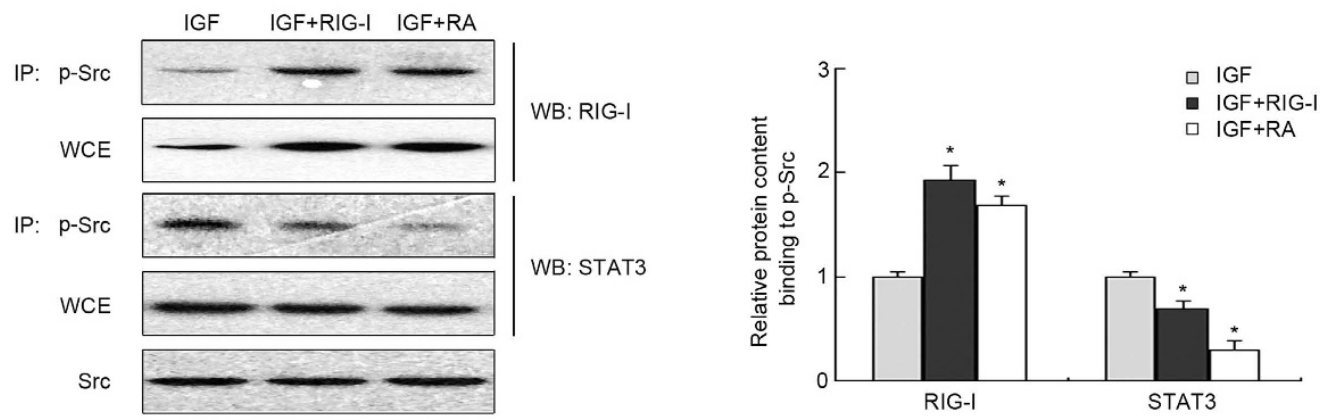

B

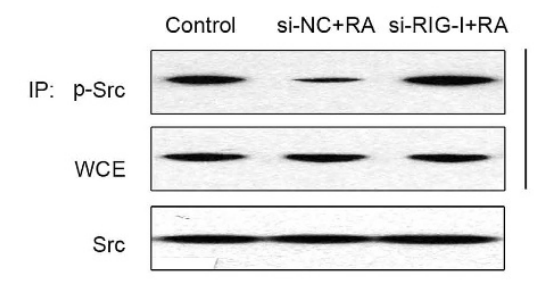

WB: STAT3

C
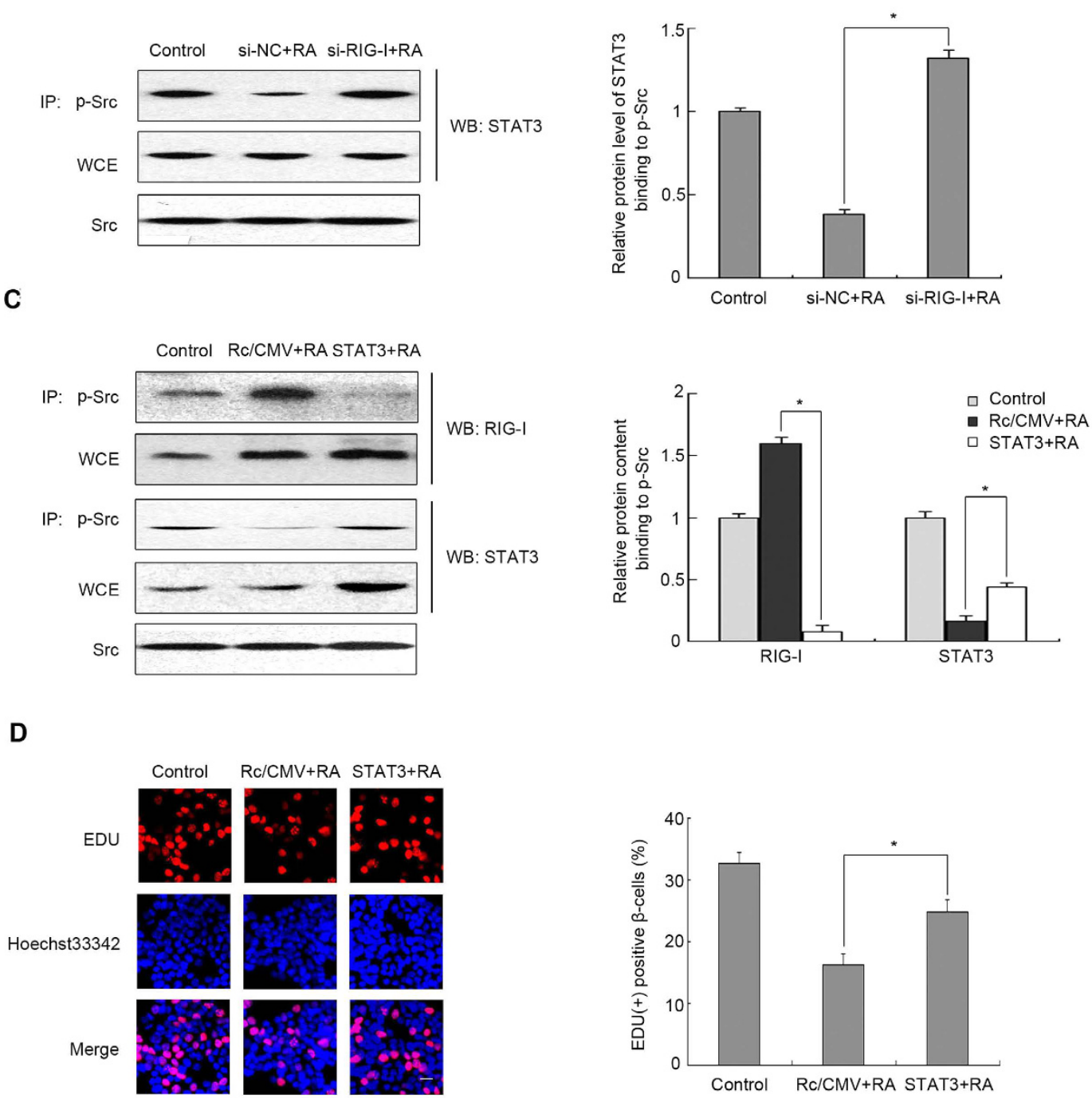

Figure 9. RIG-I interrupts the binding between Src and STAT3. (A) $24 \mathrm{~h}$ after transfection of a plasmid encoding RIG-I, Min6 cells were treated with IGF-1 or RA, as indicated. (B) RA was used to treat Min 6 cells after $24 \mathrm{~h}$ transfection of si-RIG-I. (C) Min6 cells were transfected with STAT3 for $24 \mathrm{~h}$, and then treated with RA. All these prepared extracts were immunoprecipitated with an antibody against p-Src. Immunocomplexes or whole cell extracts (WCE) were analysed by western blotting with antibodies against RIG-I or STAT3, as indicated. (D) Min6 cells were treated as in panel (C), and DNA synthesis was analysed using EdU labelling assays. Representative micrographs of EdU labelling assays in MIN6 cells are shown ( The percentage of EdU-positive $\beta$ cells was quantified. Data are means \pm SEM of three separate experiments. $* \mathrm{P}<0.05$ versus control. 
Mounting evidence suggests that the S-phase kinase-associated protein 1 (SKP1)/CUL1/F-box protein Skp2 acts as an E3 ubiquitin ligase and is involved in the ubiquitination and proteasome-dependent degradation of P2 $7^{44-47}$. Our analyses suggested the participation of Skp2 in RIG-I-mediated P27 stability. Correspondingly, Skp2 was downregulated by elevated RIG-I and glucolipotoxicity-stimulated P27 stability was abrogated when Skp2 was overexpressed (Fig. 6). Skp2 has been suggested to play a critical and specific role in regulating the cellular abundance of P27, and acts as an essential determinant of $\beta$ cell proliferation. For example, diminished $\beta$ cell mass, hypoinsulinaemia and glucose intolerance occurred in Skp2(-/-) mice ${ }^{48}$.

Meanwhile, several studies indicated that the transcript level of SKP2 depends on STAT3. STAT3 is the most well characterized signalling pathway for increasing the nuclear localization and transactivation of genes, and is thought to promote cell growth and survival through multiple mechanisms, including increased expression of oncogenes, such as c-myc, Skp2 and cyclin D1. STAT3 can regulate the transcription of Skp2 by recruiting p300 and then binding to the enhancer region of the SKP2 gene. Our studies indicated that STAT3 controlled SKP2 gene expression as an important regulator in pancreatic $\beta$-cells, in which STAT3 overexpression can reverse the decrease in the Skp2 protein levels elicited by RIG-I (Fig. 7).

STAT3 is also the downstream substrate of $\mathrm{Src}^{49,50,18}$. STAT3 can be activated by tyrosine phosphorylated Src and is then translocated to the nucleus. In the nucleus, STAT3 dimmer and tetramers bind to specific DNA response elements to induce or repress gene transcription. The transcriptional activity of STAT3 was suppressed in in vivo models of T2DM ${ }^{51,52}$. Therefore, we hypothesized that elevated RIG-I might interrupt the binding of activated Src and STAT3. The hypothesis was confirmed by the co-immunoprecipitation and immunofluorescence assays, which showed that the physical interaction between RIG-I and phospho-Src resulted in little or no binding between STAT3 and phospho-Src and that elevated RIG-I inhibited the phosphorylation of STAT3 and its translocation to the nucleus (Figs 8 and 9). Furthermore, overexpression of STAT3 could compete with RIG-I to bind with activated Src and reverse the glucolipotoxicity-induced decrease of Skp2, thereby increasing the level of P27 to abrogate the RIG-I-dependent antiproliferative effect (Figs 7 and 9). The data showed that RIG-I competitively binds active Src and then inhibits the interaction between Src and STAT3, abrogating their proliferation effect in models of T2DM.

In summary, RIG-I is significantly activated by glucolipotoxicity and metaflammation, and is implicated in $\beta$ cell mass loss through proliferation inhibition, leading to body decompensation in the course of T2DM. Via its PxxP motif, elevated RIG-I competes with STAT3 for activated Src and then blocks the Src/STAT3/Skp2 pathway to accumulate $\mathrm{P} 27$ function in pancreatic $\beta$ cells, leading to cell cycle arrest at the G1 phase. These data provide a new insight into the pathogenesis of T2DM and suggest RIG-I as a novel drug target.

\section{References}

1. Golson, M. L., Misfeldt, A. A., Kopsombut, U. G., Petersen, C. P. \& Gannon, M. High fat diet regulation of beta-Cell proliferation and beta-Cell mass. Open Endocrinol J. 4, (2010).

2. Marchetti, P. et al. Goals of treatment for type 2 diabetes: Beta-cell preservation for glycemic control. Diabetes Care 32 Suppl 2 , S178-S183 (2009).

3. Yin, J., Peng, Y., Wu, J., Wang, Y. \& Yao, L. Toll-like receptor $2 / 4$ links to free fatty acid-induced inflammation and beta-cell dysfunction. J Leukoc Biol 95, 47-52 (2014).

4. Li, X. Y. et al. RIG-I modulates Src-mediated AKT activation to restrain leukemic stemness. Mol Cell. 53, 407-419 (2014).

5. Cai, T. et al. Glucose-6-phosphate dehydrogenase and NADPH oxidase 4 control STAT3 activity in melanoma cells through a pathway involving reactive oxygen species, c-SRC and SHP2. Am J Cancer Res 5, 1610-1620 (2015).

6. Sato, Y. et al. Palmitate induces reactive oxygen species production and beta-cell dysfunction by activating nicotinamide adenine dinucleotide phosphate oxidase through Src signaling. J Diabetes Investig. 5, 19-26 (2014).

7. Alshaker, H. et al. Leptin induces upregulation of sphingosine kinase 1 in oestrogen receptor-negative breast cancer via Src family kinase-mediated, janus kinase 2-independent pathway. Breast Cancer Res. 16, 426 (2014).

8. Lin, C. C. et al. Tumor necrosis factor-alpha induces VCAM-1-mediated inflammation via c-Src-dependent transactivation of EGF receptors in human cardiac fibroblasts. J Biomed Sci. 22, 53 (2015).

9. Boekhoudt, G. H., McGrath, A. G., Swisher, J. F. \& Feldman, G. M. Immune complexes suppress IFN-gamma-induced responses in monocytes by activating discrete members of the SRC kinase family. J Immunol. 194, 983-989 (2015).

10. Chen, Q. et al. The importance of Src signaling in sarcoma. Oncol Lett. 10, 17-22 (2015).

11. Chen, B., Xu, X., Luo, J., Wang, H. \& Zhou, S. Rapamycin enhances the Anti-Cancer effect of dasatinib by suppressing Src/PI3K/ mTOR pathway in NSCLC cells. Plos One. 10, e129663 (2015).

12. Zhang, T. et al. The RNA-binding protein Sam 68 regulates tumor cell viability and hepatic carcinogenesis by inhibiting the transcriptional activity of FOXOs. J Mol Histol. 46, 485-497 (2015).

13. Chu, I. et al. P27 phosphorylation by Src regulates inhibition of cyclin E-Cdk2. Cell. 128, 281-294 (2007).

14. Kuo, C. T., Chang, C. \& Lee, W. S. Folic acid inhibits COLO-205 colon cancer cell proliferation through activating the FRalpha/cSRC/ERK1/2/NFkappaB/TP53 pathway: In vitro and in vivo studies. Sci Rep. 5, 11187 (2015).

15. Cen, B., Li, H. \& Weinstein, I. B. Histidine triad nucleotide-binding protein 1 up-regulates cellular levels of p27KIP1 by targeting ScfSKP2 ubiquitin ligase and Src. J BIOL CHEM. 284, 5265-5276 (2009).

16. Chan, C. H., Lee, S. W., Wang, J. \& Lin, H. K. Regulation of Skp2 expression and activity and its role in cancer progression. ScientificWorldJournal. 10, 1001-1015 (2010).

17. Chen, J. Y., Wang, M. C. \& Hung, W. C. Bcr-Abl-induced tyrosine phosphorylation of Emil to stabilize Skp2 protein via inhibition of ubiquitination in chronic myeloid leukemia cells. J Cell Physiol. 226, 407-413 (2011).

18. Wei, Z. et al. STAT3 interacts with Skp2/p27/p21 pathway to regulate the motility and invasion of gastric cancer cells. Cell Signal. 25, 931-938 (2013)

19. Tanti, J. F., Ceppo, F., Jager, J. \& Berthou, F. Implication of inflammatory signaling pathways in obesity-induced insulin resistance. Front Endocrinol (Lausanne). 3, 181 (2012).

20. Han, D. et al. Induction of receptor for advanced glycation end products by insufficient leptin action triggers pancreatic beta-cell failure in type 2 diabetes. Genes Cells. 18, 302-314 (2013).

21. Kim, Y. J. et al. Decreased pattern-recognition receptor-mediated cytokine mRNA expression in obese children with otitis media with effusion. Clin Exp Otorhinolaryngol. 7, 7-12 (2014)

22. Sarmiento, L. et al. Expression of innate immunity genes and damage of primary human pancreatic islets by epidemic strains of Echovirus: Implication for post-virus islet autoimmunity. Plos One. 8, e77850 (2013). 
23. Wang, Y. et al. Elevated toll-like receptor 3 inhibits pancreatic beta-cell proliferation through G1 phase cell cycle arrest. Mol Cell Endocrinol. 377, 112-122 (2013).

24. Han, X., Sun, Y., Scott, S. \& Bleich, D. Tissue inhibitor of metalloproteinase-1 prevents cytokine-mediated dysfunction and cytotoxicity in pancreatic islets and beta-cells. Diabetes. 50, 1047-1055 (2001).

25. Kang, H. C. \& Bae, Y. H. Transfection of rat pancreatic islet tissue by polymeric gene vectors. Diabetes Technol Ther. 11, 443-449 (2009).

26. Gao, L. et al. Protein-Binding Function of RNA-Dependent Protein Kinase Promotes Proliferation through TRAF2/RIP1/NFkappaB/c-Myc Pathway in Pancreatic beta cells. Mol Med. 21, 154-166 (2015).

27. Gu, L. et al. Early activation of nSMase2/ceramide pathway in astrocytes is involved in ischemia-associated neuronal damage via inflammation in rat hippocampi. J Neuroinflammation. 10, 109 (2013).

28. Chen, S. S. et al. Activation of double-stranded RNA-dependent protein kinase inhibits proliferation of pancreatic beta-cells. Biochem Biophys Res Commun. 443, 814-820 (2014).

29. Meng, Z. X. et al. Activation of liver X receptors inhibits pancreatic islet beta cell proliferation through cell cycle arrest. Diabetologia. 52, 125-135 (2009).

30. Feng, X. et al. Functional characterizations of IPS-1 in CIK cells: Potential roles in regulating IFN-I response dependent on IRF7 but not IRF3. Dev Comp Immunol. 53, 23-32 (2015).

31. Min, H. Y. et al. Targeting the insulin-like growth factor receptor and Src signaling network for the treatment of non-small cell lung cancer. Mol Cancer. 14, 113 (2015).

32. Huang, H., Zhao, W. \& Yang, D. Stat3 induces oncogenic Skp2 expression in human cervical carcinoma cells. Biochem Biophys Res Commun. 418, 186-190 (2012).

33. Schreiner, S. J., Schiavone, A. P. \& Smithgall, T. E. Activation of STAT3 by the Src family kinase Hck requires a functional SH3 domain. J Biol Chem. 277, 45680-45687 (2002).

34. Kominato, R. et al. Src activation generates reactive oxygen species and impairs metabolism-secretion coupling in diabetic GotoKakizaki and ouabain-treated rat pancreatic islets. Diabetologia. 51, 1226-1235 (2008).

35. Matsumoto, T., Kobayashi, T., Ishida, K., Taguchi, K. \& Kamata, K. Enhancement of mesenteric artery contraction to 5-HT depends on Rho kinase and Src kinase pathways in the ob/ob mouse model of type 2 diabetes. Br J Pharmacol. 160, 1092-1104 (2010).

36. Gupte, R. S. et al. Synergistic activation of glucose-6-phosphate dehydrogenase and NAD(P)H oxidase by Src kinase elevates superoxide in type 2 diabetic, Zucker fa/fa, rat liver. Free Radic Biol Med. 47, 219-228 (2009).

37. Je, D. W., O, Y. M., Ji, Y. G., Cho, Y. \& Lee, D. H. The inhibition of SRC family kinase suppresses pancreatic cancer cell proliferation, migration, and invasion. Pancreas. 43, 768-776 (2014).

38. Song, Y. et al. Activated PKR inhibits pancreatic beta-cell proliferation through sumoylation-dependent stabilization of P53. Mol Immunol. 68, 341-349 (2015).

39. Matikainen, S. et al. Tumor necrosis factor alpha enhances influenza a virus-induced expression of antiviral cytokines by activating RIG-I gene expression. J Virol. 80, 3515-3522 (2006).

40. Malin, S. K., Kirwan, J. P., Sia, C. L. \& Gonzalez, F. Glucose-stimulated oxidative stress in mononuclear cells is related to pancreatic beta-cell dysfunction in polycystic ovary syndrome. J Clin Endocrinol Metab. 99, 322-329 (2014).

41. Tal, M. C. et al. Absence of autophagy results in reactive oxygen species-dependent amplification of RLR signaling. Proc Natl Acad Sci USA 106, 2770-2775 (2009).

42. Aida, K. et al. RIG-I- and MDA5-initiated innate immunity linked with adaptive immunity accelerates beta-cell death in fulminant type 1 diabetes. Diabetes. 60, 884-889 (2011).

43. Prasad, S. B. et al. PI3K/AKT pathway-mediated regulation of p27(Kip1) is associated with cell cycle arrest and apoptosis in cervical cancer. Cell Oncol (Dordr). 38, 215-225 (2015).

44. Su, L., Han, D., Wu, J. \& Huo, X. Skp2 regulates non-small cell lung cancer cell growth by Meg3 and miR-3163. Tumour Biol (2015).

45. Hafez, M. M. et al. SKP2/P27Kip1 pathway is associated with Advanced Ovarian Cancer in Saudi Patients. Asian Pac J Cancer Prev. 16, 5807-5815 (2015).

46. Hnit, S. S. et al. P27(Kip1) signaling: Transcriptional and post-translational regulation. Int J Biochem Cell Biol. 68, 9-14 (2015).

47. Liu, Y. et al. A relationship between p27(kip1) and Skp2 after adult brain injury: Implications for glial proliferation. J Neurotrauma. 27, 361-371 (2010)

48. Zhong, L. et al. Essential role of Skp2-mediated p27 degradation in growth and adaptive expansion of pancreatic beta cells. J Clin Invest 117, 2869-2876 (2007).

49. Lee, J. J. et al. BIS targeting induces cellular senescence through the regulation of 14-3-3 zeta/STAT3/SKP2/p27 in glioblastoma cells. Cell Death Dis. 5, e1537 (2014).

50. Koo, K. H. et al. Salinomycin induces cell death via inactivation of Stat3 and downregulation of Skp2. Cell Death Dis. 4, e693 (2013).

51. Kou, Z. Z. et al. Down-regulation of insulin signaling is involved in painful diabetic neuropathy in type 2 diabetes. Pain Physician. 16, E71-E83 (2013).

52. Pan, Q. et al. Metformin can block precancerous progression to invasive tumors of bladder through inhibiting STAT3-mediated signaling pathways. J Exp Clin Cancer Res. 34, 77 (2015).

\section{Acknowledgements}

Plasmids encoding RIG-I was provided by Michael J Gale, Jr (University of Washington), Skp2 was provided by Viktoriya Marusyk (Prof. Pandolfi laboratory), and STAT3 was provided by Jun Wan (University of Science and Technology, Hong Kong, China). The work was supported by grants from the National Natural Science Foundation of China (Nos 81573409, 81170714).

\section{Author Contributions}

J.G. and L.G. designed the experiments. Y.P. and G.L. carried out the experiments. H.Z. and M.C. analysed the experimental results. T.C. and H.W. developed the analysis tools. Y.P. and G.L. wrote the manuscript. Y.P. and G.L. contributed equally to this paper. All authors reviewed the manuscript.

\section{Additional Information}

Supplementary information accompanies this paper at http://www.nature.com/srep

Competing financial interests: The authors declare no competing financial interests.

How to cite this article: Pan, Y. et al. RIG-I inhibits pancreatic $\beta$ cell proliferation through competitive binding of activated Src. Sci. Rep. 6, 28914; doi: 10.1038/srep28914 (2016). 
(c) (i) This work is licensed under a Creative Commons Attribution 4.0 International License. The images or other third party material in this article are included in the article's Creative Commons license, unless indicated otherwise in the credit line; if the material is not included under the Creative Commons license, users will need to obtain permission from the license holder to reproduce the material. To view a copy of this license, visit http://creativecommons.org/licenses/by/4.0/ 